\title{
Downhole distributed acoustic seismic profiling at Skytrain Ice Rise, West Antarctica
}

\author{
Alex M. Brisbourne ${ }^{1}$, Michael Kendall ${ }^{2}$, Sofia-Katerina Kufner ${ }^{1}$, Thomas S. Hudson ${ }^{2}$, and Andrew M. Smith ${ }^{1}$ \\ ${ }^{1}$ IDP, NERC British Antarctic Survey, Cambridge, CB3 0ET, UK \\ ${ }^{2}$ Department of Earth Sciences, University of Oxford, Oxford, OX1 3AN, UK
}

Correspondence: Alex M. Brisbourne (aleisb@bas.ac.uk)

Received: 4 January 2021 - Discussion started: 28 January 2021

Revised: 1 June 2021 - Accepted: 24 June 2021 - Published: 23 July 2021

\begin{abstract}
Antarctic ice sheet history is imprinted in the structure and fabric of the ice column. At ice rises, the signature of ice flow history is preserved due to the low strain rates inherent at these independent ice flow centres. We present results from a distributed acoustic sensing (DAS) experiment at Skytrain Ice Rise in the Weddell Sea sector of West Antarctica, aimed at delineating the englacial fabric to improve our understanding of ice sheet history in the region. This pilot experiment demonstrates the feasibility of an innovative technique to delineate ice rise structure. Both direct and reflected P- and S-wave energy, as well as surface wave energy, are observed using a range of source offsets, i.e. a walkaway vertical seismic profile, recorded using fibre optic cable. Significant noise, which results from the cable hanging untethered in the borehole, is modelled and suppressed at the processing stage. At greater depth where the cable is suspended in drilling fluid, seismic interval velocities and attenuation are measured. Vertical P-wave velocities are high $\left(V_{\mathrm{INT}}=3984 \pm 218 \mathrm{~m} \mathrm{~s}^{-1}\right)$ and consistent with a strong vertical cluster fabric. Seismic attenuation is high $\left(Q_{\mathrm{INT}}=75 \pm 12\right)$ and inconsistent with previous observations in ice sheets over this temperature range. The signal level is too low, and the noise level too high, to undertake analysis of englacial fabric variability. However, modelling of $\mathrm{P}$ - and $\mathrm{S}$-wave travel times and amplitudes with a range of fabric geometries, combined with these measurements, demonstrates the capacity of the DAS method to discriminate englacial fabric distribution. From this pilot study we make a number of recommendations for future experiments aimed at quantifying englacial fabric to improve our understanding of recent ice sheet history.
\end{abstract}

\section{Introduction}

Uncertainties in sea level rise projections are dominated by our understanding of how the ice sheets will evolve under a warming climate (IPCC, 2013). Satellite observations over the last 40 years have highlighted the rate of ongoing ice sheet change (Shepherd et al., 2018; Rignot et al., 2019). However, knowledge of past ice sheet change is key to reducing uncertainty in projections of the future behaviour of the ice sheets (Siegert et al., 2019). One key region of West Antarctica where consensus on ice sheet history is yet to be reached is the Weddell Sea sector. Contradictory and incompatible recent histories have been proposed. Hillenbrand et al. (2014) reviewed geological observations, as well as marine and terrestrial chronological data, and proposed a monotonic ice sheet retreat since the Last Glacial Maximum (LGM) to the current grounding line position. However, studies utilising airborne radar surveys (Siegert et al., 2013), ground-based radar and radiocarbon dating (Kingslake et al., 2018), and ice sheet modelling (Bradley et al., 2015) support ice sheet retreat from the LGM to beyond the current grounding line configuration followed by a more recent re-advance. Due to a paucity of absolute dating control, the timing of these changes is also poorly constrained.

Significantly, these contradictory histories imply different stability regimes of the ice sheet in its current configuration, with important implications for a much discussed process: the marine ice sheet instability mechanism, or MISI (Mercer, 1978). MISI describes a feedback mechanism whereby ice streams resting on a reverse bed slope (i.e. deepening upstream) accelerate during retreat. The instability results from an increase in flux at the grounding line as the bed deepens, 
and ice thickness at the grounding line increases as the ice stream retreats. In the Weddell Sea sector, both the Institute and Möller ice streams, for example, rest on a bed which deepens upstream (Ross et al., 2012). An ice sheet history with monotonic retreat indicates that the current ice sheet configuration may be unstable, with MISI potentially underway. On the contrary, an ice sheet history that includes retreat beyond the current grounding line position with subsequent re-advance to the present-day position demonstrates that the MISI process may be stabilised. For example, in the Amundsen Sea sector, geodetic observations and modelling results demonstrate that the solid-Earth response to rapid ice loss may result in the stabilisation of retreat (Larour et al., 2019; Barletta et al., 2018).

Ice flow history is recorded within the structure of the ice column (Conway et al., 1999). Where ice flow is slow, such as at ice rises and divides, the ice structure may be analysed to understand recent ice flow. Ice rises form independent ice flow centres, with characteristic gravity-driven flow originating at the apex (Matsuoka et al., 2015). The stratigraphy of the ice column at the ice divide records this ice flow and may be emulated using numerical ice flow models (e.g. Martin et al., 2009; Raymond, 1983; Conway et al., 1999). Deviation from the expected structure may be used to infer changes in ice flow (Wearing and Kingslake, 2019; Kingslake et al., 2016; Nereson et al., 1998; Martin et al., 2006).

Ice crystals are strongly anisotropic; the shear strength parallel to the c axis of hexagonal ice crystals is several orders of magnitude greater than perpendicular to it, resulting in $c$ axis rotation during the deformation of polycrystalline aggregates (Alley, 1988; Duval et al., 1983). Under differential stress, the $c$ axes rotate towards the compressional and away from tensional axes, resulting in crystal preferred orientation (CPO), or fabric, that is characteristic of the stress regime (Azuma and Higashi, 1985). At a perfect ice dome where ice deforms by vertical uniaxial compression alone, a cluster fabric with $c$ axes orientated towards the vertical results (e.g. Azuma et al., 1999; Durand et al., 2007). At ice divides, where a lateral component of tension is present, a vertical girdle fabric also develops, with the $c$ axes rotated to form a diffuse girdle orthogonal to the direction of extension (e.g. Lipenkov et al., 1989; Bargmann et al., 2012). The nature of fabric at ice domes and ice divides has been confirmed using laboratory measurements of ice cores (Weikusat et al., 2017; Montagnat et al., 2012; Thorsteinsson et al., 1997; Wang et al., 2003). Numerical modelling results of Martin et al. (2009) demonstrate that ice divide fabrics require at least 4 times the characteristic time to develop, in which the characteristic time is the ratio of ice thickness to accumulation rate. The time taken to overprint a pre-existing fabric is poorly constrained and dependent on temperature and strain rate. However, at low strain rates and in the absence of recrystallisation it will take significant time to eradicate existing fabric. Therefore, a complex strain history leads to a complex fabric (Alley, 1988), and observations of fabric, as well as structure at ice divides, may be used to interpret ice flow history (Brisbourne et al., 2019).

The most widely used method to determine fabric at ice divides is the analysis of ice cores. However, recovery of ice cores is logistically complex and expensive. In addition, measurements of fabric in ice cores generally do not include the in situ orientation as this is lost during retrieval of the core. It is therefore desirable to measure fabric in situ. By extension, it may also be desirable to measure fabric when an ice core has not been recovered during a drilling campaign, such as following the use of a hot water drill or a rapid access drill which recovers ice chippings rather than an ice core (Rix et al., 2019). Surface geophysics methods and downhole measurements are therefore required. The depth distribution of fabric has previously been investigated using surface seismic reflection methods (Horgan et al., 2011, 2008; Blankenship and Bentley, 1987; Bentley, 1972) and radar methods (Hargreaves, 1977; Fujita et al., 2006; Doake et al., 2002). With passive seismic methods, deriving the depth distribution of fabric is not always possible (Smith et al., 2017). Additional constraints on fabric type and distribution within the ice column may be achieved using measurements at depth within the ice column. Direct access to the deep ice column is logistically difficult, expensive and risky. However, large-scale ice core or hot water drilling experiments potentially provide access to the subsurface as a by-product of the primary objectives of the experiment. Although it is feasible to deploy three-component borehole seismometers if holes are sufficiently wide, these systems are expensive and, depending on the number of instruments deployed, provide measurements at a limited number of depths within the ice column (Lutz et al., 2020). To compensate for this limitation, Diez et al. (2015) moved a single downhole geophone incrementally up through an ice core borehole with repeat surface shooting to produce a vertical seismic profile (VSP). Comparing these results with radar and ice core analysis results, they identified both strong cluster and girdle fabric at an ice divide site and demonstrated consistency between the methods. Downhole geophysical measurements remain sparse in glacial settings (e.g. Obbard et al., 2011; Hubbard et al., 2020; Raymond, 1971; Hubbard et al., 1998; Roberson and Hubbard, 2010), reflecting the logistical challenges of such methods. Again, such systems require access to a sufficiently wide and uniform borehole without the risk of hole closure, which is often not the case with hot water drilling in dynamic ice flow regimes, for example.

However, following ice core recovery or hot water drill access, it is now common practice to deploy fibre optic cables downhole to measure temperature profiles within the ice column using the distributed temperature sensing (DTS) method (Ukil et al., 2012). Distributed acoustic sensing (DAS) provides an opportunistic method to exploit existing infrastructure, enabling downhole measurements at little extra cost and minimal risk. Furthermore, measurements using DAS may be acquired throughout the ice column, are capable of sub-metre 
sample intervals and, if the fibre optic cable remains in situ, are readily repeatable to allow analysis of temporal variation. DAS involves measuring the Rayleigh backscattered returns along optical fibre cables. Time-varying strain of the fibre, such as that from passing seismic waves, is derived from changes in the phase difference in backscattered light from closely spaced points along the fibre. The phase lags measured by an interrogator are used to reconstruct the seismic record (Hartog, 2017). The distributed nature of the Rayleigh scatterers within the fibre emulates a continuous geophone string. Such records are analogous to standard seismic methods, but unlike with standard geophone sensors, they measure strain rate rather than velocity. Where a fibre optic cable is deployed down a borehole, the DAS method can be used to derive a VSP. Standard seismic processing methods are then applied to calculate, for example, seismic interval velocities from the travel time through layers of known thickness. Fibre optic cables are termed single-mode (with a light carrying core of 8-10 $\mu \mathrm{m}$ ) or multi-mode (with a light carrying core of $>50 \mu \mathrm{m}$ ). Due to multiple paths within the fibre, multi-mode fibre results in signal dispersion, reduced range and lower bandwidth. However, multi-mode fibre produces a higher threshold for non-linearities and allows more power to be applied to the fibre, resulting in stronger backscatter signals, and is therefore preferred by some manufacturers for certain applications, such as DTS. The backscattered signal used in DAS is stronger than DTS, and therefore single-mode systems are commonly used for DAS measurements. A fibre optic cable may also utilise a "bend" whereby two lengths of fibre may be spliced together to form an outward and return fibre within the same cable, thereby allowing two measurements to be made at each point along a cable with a single interrogator unit. Although measurements may be reported with a channel spacing of 0.25 or $1 \mathrm{~m}$, for example, strain is measured over a finite length of fibre, or spatial distance, referred to as the gauge length, and is typically 3 or $10 \mathrm{~m}$. The gauge length is therefore effectively a moving spatial average filter applied to measurements at the channel spacing.

To our knowledge, DAS technology has been deployed only twice previously in glaciological studies and never in Antarctica. Booth et al. (2020) presented results from a VSP with borehole deployment of DAS on Store Glacier, West Greenland. Measurements of interval seismic velocity and attenuation, as well as sub-glacial reflections, demonstrated the potential of the DAS method in glaciological settings. Using a deployment of fibre optic cable on an alpine glacier surface, Walter et al. (2020) demonstrated the capacity of the method to record naturally occurring glacial seismicity and demonstrated the capacity for these observations to locate icequakes and delineate physical properties of the glacier and its bed. We present results from the first field deployment of DAS in an Antarctic borehole. We occupied a recent ice core site to evaluate the potential of DAS technology to constrain the seismic structure of the ice column at an Antarctic ice rise with the aim of improving understanding of ice sheet his- tory. We demonstrate the capability of the method in such scenarios with field observations, highlight the potential for the method to discriminate englacial structure through modelling and make recommendations for future deployments in similar situations.

\section{Field setting and data acquisition}

Skytrain Ice Rise (SIR) in the Weddell Sea region of West Antarctica is an independent ice flow centre adjacent to the Filchner-Ronne Ice Shelf, bounded by the fast-flowing Rutford and Institute ice streams, Constellation and Hercules inlets, and the southern end of the Ellsworth-Whitmore Mountains (Fig. 1a, b). In 2018/2019, as part of the WACSWAIN Project (Mulvaney et al., 2021), an ice core was recovered to bedrock at $651 \mathrm{~m}$ depth close to the highest point of the ice rise (Fig. 1b). The experiment site is directly above a Raymond bump visible in radar profile data (Mulvaney et al., 2021), a feature observed within the ice column that is indicative of long-term stable ice flow. Surface ice flow speed is $<10 \mathrm{~m} \mathrm{a}^{-1}$ (Rignot et al., 2011). Following extraction of the ice core, three cables were deployed in the borehole: (1) a thermistor string to a depth of $635 \mathrm{~m}$ with instruments at known depths $(635,585,535,385$ and $235 \mathrm{~m})$; (2) a PT100 platinum resistance thermometer to $95 \mathrm{~m}$ depth, and (3) a multi-mode fibre optic cable to $595 \mathrm{~m}$ depth, principally for DTS. The three cables were joined at $5 \mathrm{~m}$ intervals. The borehole remained open due to a combination of slow ice flow at the ice divide and the presence of drilling fluid in approximately the lower half of the borehole (exact depth unknown).

In January 2020 the site was revisited to conduct a VSP experiment centred on the borehole using a Silixa iDAS ${ }^{\mathrm{TM}}$ interrogator unit with GPS timing. A $1.0 \mathrm{kVA}$ petrol generator was used to power the interrogator unit. The interrogator was housed in a tent to protect it from the wind and maintain a working temperature. Data were recorded at $8000 \mathrm{~Hz}$ sampling frequency. Strain rate measurements were made at $1 \mathrm{~m}$ intervals along the fibre but with an effective resolution of $10 \mathrm{~m}$ due to the "gauge length" or strain rate averaging process (Dean et al., 2017). The fibre optic cable includes a bend at $595 \mathrm{~m}$, where an identical length of fibre within the cable is spliced and returned to the surface, enabling two measurements to be made at each depth. The DAS method measures longitudinal strain. Therefore, with the fibre optic cable vertical, only the vertical strain component of seismic waves propagating past the fibre is measured. Consequently, the cable is sensitive to vertically propagating $\mathrm{P}$-waves but not vertically propagating $\mathrm{S}$-waves.

The acquisition geometry is presented in Fig. 1c. With the aim of discriminating anisotropic structure within the ice column, three walkaway profiles were acquired at $45^{\circ}$ to one another. Line names reference the orientation with respect to magnetic north. A $4.5 \mathrm{~kg}$ sledgehammer with a rigid polyethylene impact plate stamped into the snow sur- 

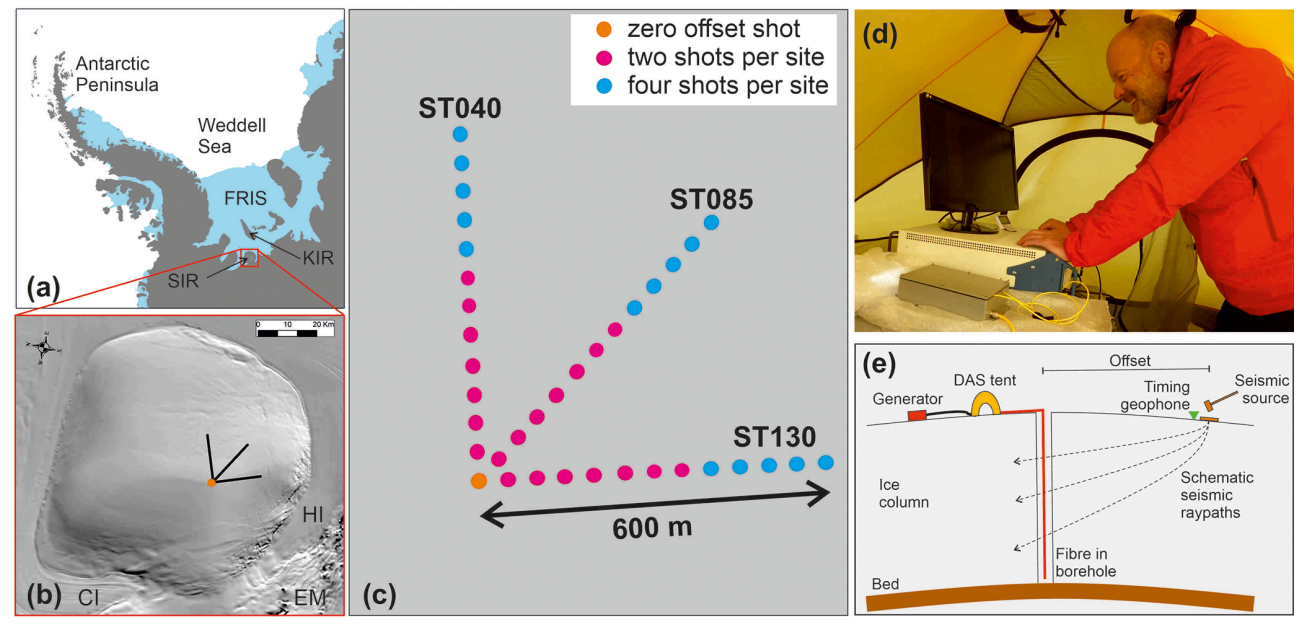

Figure 1. (a) Location of the experiment (red dot) on SIR in West Antarctica. FRIS - Filchner-Ronne Ice Shelf; KIR - Korff Ice Rise. (b) Orientation of walkaway hammer and plate seismic lines on SIR (not to scale). The background is MODIS imagery (Scambos et al., 2007). HI - Hercules Inlet; CI - Constellation Inlet; EM - Ellsworth-Whitmore Mountains. (c) Scale map of shot locations with respect to the borehole at $79^{\circ} 44.5^{\prime} \mathrm{S}, 078^{\circ} 32.7^{\prime} \mathrm{W}$ (orange dot). Line names reference the orientation with respect to magnetic north. (d) DAS interrogator in a mountain tent. (e) Schematic of acquisition illustrating the key components of the field set-up.

face acted as the energy source. Hammer impact times were derived from a continuous $1000 \mathrm{~Hz}$ record of a GPSsynchronised three-component surface geophone deployed adjacent to the hammer plate (Fig. 1e). Profiles were acquired out to $600 \mathrm{~m}$ offset from the borehole with hammer blows at $50 \mathrm{~m}$ intervals. Two hammer blows were made at each shot point out to $350 \mathrm{~m}$ and four hammer blows from $400 \mathrm{~m}$ and beyond. The interrogator unit recorded in continuous mode with shot gathers subsequently extracted using times derived from impulsive arrivals on the surface geophone recording made adjacent to the hammer plate.

\section{Observations and data processing}

Figure 2 presents example VSP records for individual hammer blows at a range of offsets along line ST130. Data are "folded" about the bend in the cable, resulting in a stack of two traces for each hammer blow. Figure $2 \mathrm{a}$ presents the zero offset or "checkshot" (i.e. source at the top of the borehole) bandpass filtered at $2-140 \mathrm{~Hz}$. The downwards propagating P-wave, the primary ice base reflection and the surface multiple are all visible. The primary downwards-propagating $\mathrm{P}$-wave arrival is disrupted at around $350 \mathrm{~m}$ depth. A mixture of upgoing and downgoing energy is observed at 100$300 \mathrm{~m}$ depth following the primary P-wave arrival, producing a diamond-shaped signal pattern on a depth-time plot. From zero to $150 \mathrm{~ms}$, prior to the primary downgoing P-wave arrival, a horizontal signal is observed in Fig. 2a. A signal that plots horizontally in a VSP record indicates an arrival coincident in time along the length of the fibre optic cable. This is however unlikely in this situation and is most likely due to vibration of the DAS interrogator unit, a result of wind and generator noise at the surface.

Figure $2 \mathrm{~b}$ presents the checkshot record as presented in Fig. 2a but with a frequency-wavenumber (f-k) filter applied to suppress upward propagating seismic energy (negative wavenumber energy removed, $2-140 \mathrm{~Hz}$ bandpass) and with an adaptive deconvolution filter (Griffiths et al., 1977) applied to remove coherent noise. The upgoing energy is removed, but the primary P-wave energy remains discontinuous with the wave train disrupted. The combined upgoing and downgoing signal at approximately $100-300 \mathrm{~m}$ depth is suppressed by the combination of the f-k and adaptive deconvolution filters. However, some upgoing energy persists at depths of less than $300 \mathrm{~m}$. Over a shorter time interval and shallower depth range, Fig. 2c presents details of the VSP record acquired with a shot offset of $200 \mathrm{~m}$ on line ST130. A $2-140 \mathrm{~Hz}$ bandpass filter is applied. Again, the downgoing P-wave energy is clear, with a delay due to the source offset from the fibre. Relatively high-amplitude but low-frequency energy is present to depths of $100 \mathrm{~m}$. The characteristic diamond pattern is again observed, to a depth of up to $250 \mathrm{~m}$, indicating both upgoing and downgoing energy. Figure $2 \mathrm{~d}$ presents the VSP with a shot offset of $400 \mathrm{~m}$ and a $2-140 \mathrm{~Hz}$ bandpass filter applied. At this offset, seismic waves propagate more horizontally. Therefore, downgoing S-wave energy dominates the record with downgoing P-wave energy only visible beyond approximately $300 \mathrm{~m}$ depth.

\subsection{Noise sources}

Figure 3a presents a single VSP from a $200 \mathrm{~m}$ offset shot along line ST130. The downgoing P-wave is visible at depths below $200 \mathrm{~m}$ and the downgoing S-wave at 150 to $230 \mathrm{~m}$. 

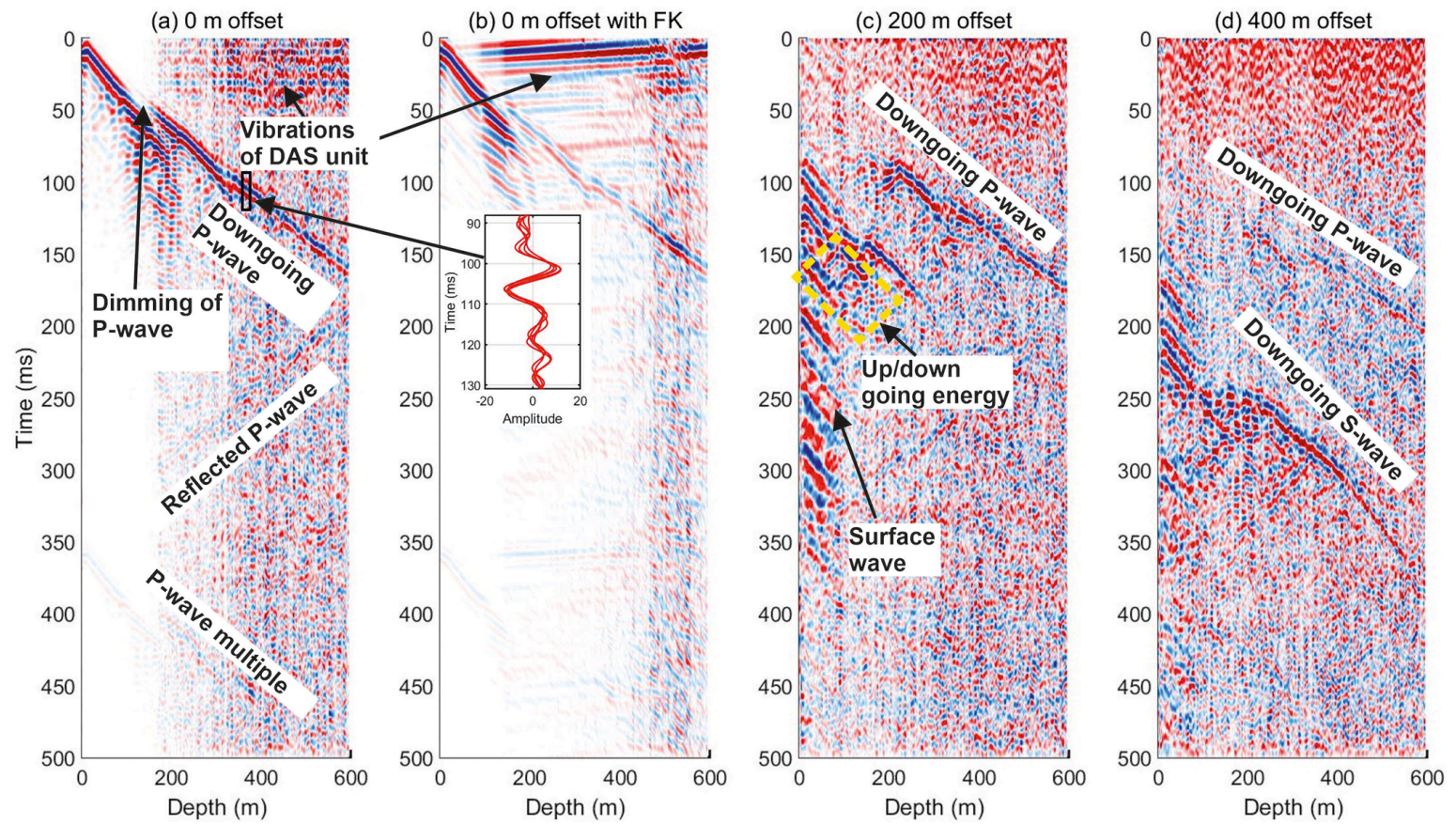

Figure 2. Example DAS VSPs along line ST130 with signal and noise labelled. Traces are normalised at each depth to highlight coherent arrivals. This also results in the dimming of signals over depths with high amplitude arrivals dominating. (a) Primary, reflected and surfacemultiple P-waves at zero offset with a bandpass filter of $2-140 \mathrm{~Hz}$. Vibrations from the generator and wind noise of the DAS interrogator appear as horizontal lines in these sections. The apparent dimming of the P-wave at $50 \mathrm{~ms}$ is due to the high amplitudes of the following signals. (b) Downgoing P-wave energy at zero offset isolated using an f-k filter and adaptive deconvolution to remove upgoing energy and reduce coherent noise. Some upgoing energy is preserved due to the taper used on the f-k filter. Inset: example waveforms of five downgoing P-waves at $100 \mathrm{~ms}$ and $350 \mathrm{~m}$ depth, indicated by the black box in (a) (no f-k filter applied). (c) Source at $200 \mathrm{~m}$ offset with a bandpass filter of $2-140 \mathrm{~Hz}$. The characteristic diamond-pattern is highlighted by the dashed yellow box. (d) Both P-wave and S-wave arrivals are visible at $400 \mathrm{~m}$ source offset with bandpass filter of $2-140 \mathrm{~Hz}$ applied.

A low-frequency signal is also visible at times greater than $150 \mathrm{~ms}$ and from the surface to a depth of $100 \mathrm{~m}$. As described above, significant noise is present on the records at depths of less than $300 \mathrm{~m}$. This takes the form of "diamond shapes" indicating a combination of upgoing and downgoing energy. The most obvious source of signals of this type is englacial reflections of downgoing energy. However, a number of factors indicate a different noise source of such signals. The firn column consists of snow compacting, metamorphosing and densifying under its own weight to form solid ice, with a pore close-off depth at SIR of $56 \mathrm{~m}$ (Mulvaney et al., 2021). Below this depth the ice column likely varies very little at scales sensitive to the seismic wavelengths analysed here $(\lambda \sim 36 \mathrm{~m})$, and the seismic velocity is predominantly controlled by temperature, which varies slowly. The low temperatures at SIR $\left(-26.0^{\circ} \mathrm{C}\right.$ at $10 \mathrm{~m}$ depth; Mulvaney et al., 2021) preclude ice layers in the firn. Therefore, there is no likely source of layering which could result in seismic reflections of any significance from within the ice column. Similarly, the stress regime precludes englacial crevassing. No structures are observed in the radar profile collected across SIR (Mulvaney et al., 2021, Fig. 3).
We therefore propose a different source for the diamondshaped signal. As stated above, the hole remains open. The fibre optic cable is unlikely to be frozen to the borehole (Robert Mulvaney, personal communication, 2020). This is in contrast to the experiment of Booth et al. (2020) in which the borehole closed up within a few days. Prior to close-up of the borehole, Booth et al. (2020) observed a similar diamondshaped signal pattern in the VSP data. We therefore attribute this noise to the fibre being unclamped in the hole and hanging in air. At depths where the drilling fluid is present (below around $300 \mathrm{~m}$ ) the fibre optic cable sits in the fluid and couples to the walls of the hole via the fluid. At these depths we can expect lower noise levels due to damping of vibrations of the cable and improved signal coupling. This is indeed the case in our data in which we see a transition at around $300 \mathrm{~m}$ depth. This depth also coincides with a discontinuity in the primary $\mathrm{P}$-wave arrival, consistently observed over a range of shot offsets and azimuths. The onset of diamond-shaped noise is coincident with the first $\mathrm{P}$-wave arrival, in this case at around $50 \mathrm{~ms}$, and we therefore attribute noise of this form to the excitation of vibrations on the cables by seismic energy passing the borehole. 

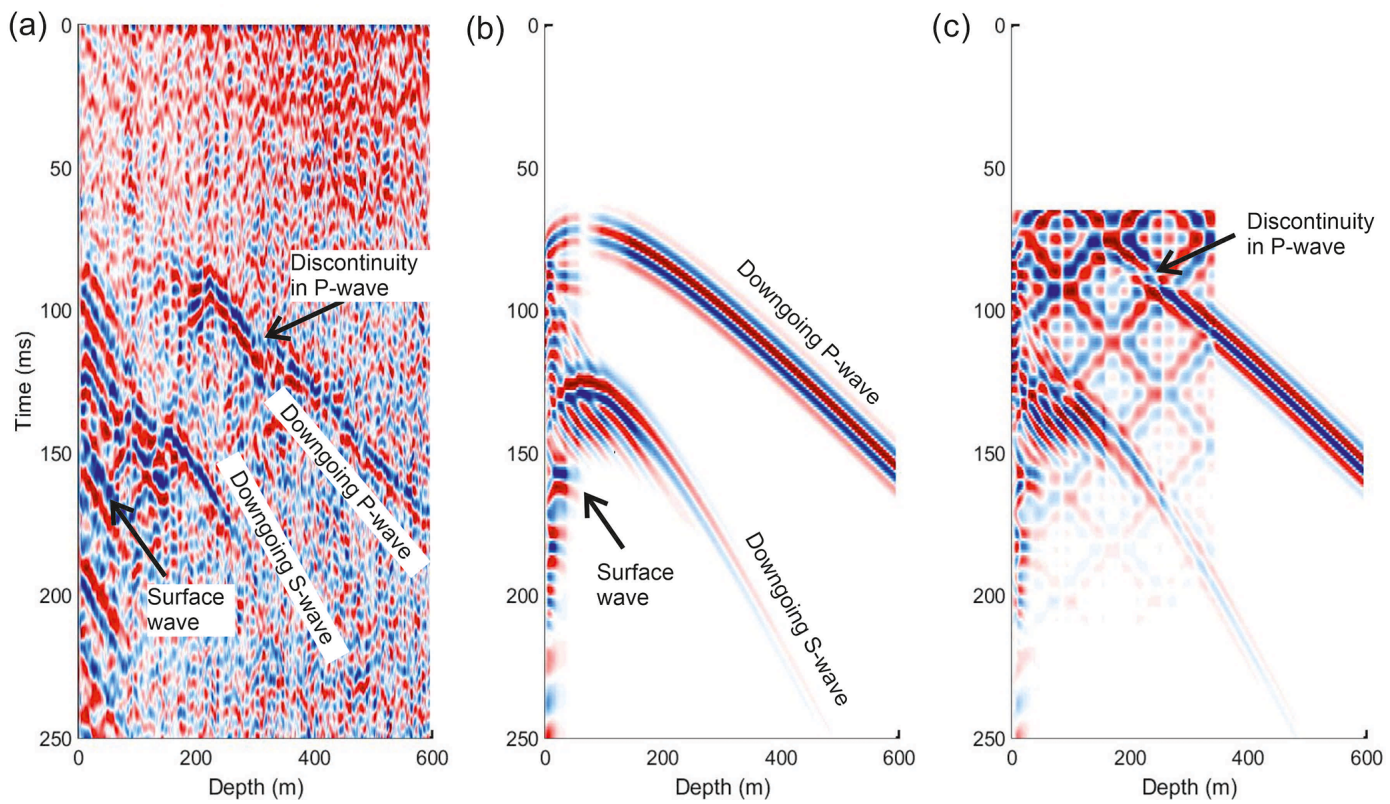

Figure 3. Observed and synthetic VSPs with a shot offset of $200 \mathrm{~m}$ from the top of the borehole along line ST130. Traces are normalised at each depth. (a) Observed VSP with a $2-140 \mathrm{~Hz}$ bandpass filter applied. (b) Synthetic VSP with the principal arrivals labelled. (c) Synthetic VSP summed with simple harmonic motion of a vibrating string fixed at both ends ( 0 and $340 \mathrm{~m})$.

To test this hypothesis we construct full-waveform synthetics to simulate VSP records with added coherent noise due to cable resonance. Figure $3 \mathrm{~b}$ shows a synthetic VSP simulating a $200 \mathrm{~m}$ offset shot into a $600 \mathrm{~m}$ downhole fibre optic cable. We use SPECFEM2D current source (Tromp et al., 2008) published under the CeCILL V2 license. We convert the synthetic seismogram from velocity to strain rate to emulate DAS measurements. We assume the seismic velocity profile as measured at the adjacent Korff Ice Rise (Brisbourne et al., 2019). In this synthetic VSP (Fig. 3b), clear $\mathrm{P}$ - and S-wave energy is observed, consistent with the observations. The low-frequency surface waves in the synthetic seismogram are coincident with a low-frequency arrival in the observations (Fig. 3a). We hypothesise that as the surface wave traverses the borehole, it excites a mode of vibration on the fibre that propagates its length, resulting in a consistent noise signature across the range of shots. We argue that this signal is not a depth observation of the surface wave due to slope of the arrival in Fig. 2c. A surface wave traversing the fibre would appear coincident along the fibre, i.e. with a horizontal nature in the VSP.

In Fig. $3 \mathrm{c}$ we present the sum of the synthetic seismogram and a synthetic noise signal generated assuming simple harmonic motion (SHM) on a string of length $340 \mathrm{~m}$ fixed at both ends and with nodes at $85 \mathrm{~m}$ intervals. These parameters are set at values that produce a reasonable simulation of the observations and are not intended to match the conditions down the borehole, which are poorly constrained. We scale the amplitude of the SHM to produce a representative match to the data and apply exponential decay with time to this signal. We initiate the synthetic SHM at the arrival time of the P-wave at the borehole. The SHM produces the characteristic diamond-shaped signal as observed in the VSPs. The summation of the synthetic seismogram and noise also produces nulls in the resultant direct wave train, similar to those observed in the data. The synthetic profile is not an exact representation of the observations. However, similarities with the observations indicate that the most likely source of this diamond-shaped noise is vibrations on the cables suspended in air, initiated by the propagation of the seismic signal past the borehole.

Unfortunately, the effect of cable resonance in the open parts of the borehole (surface to $\sim 350 \mathrm{~m}$ depth) render it difficult to use data from this section of the cable in an analysis of seismic properties of the ice column. Hence, we only expect reliable results from the cable in the deeper parts of the borehole ( 350 to $550 \mathrm{~m}$ depth). To improve signal to noise levels for further data analysis, the "folded" shot records are stacked to combine all hammer blows at each shot point.

\section{Data analysis and results}

\subsection{Seismic velocity}

Prior to velocity analysis we apply an f-k filter, passing 2$140 \mathrm{~Hz}$ and removing negative wavenumbers to reduce upgoing energy. We also apply an adaptive deconvolution filter to remove coherent noise. Travel time picks are made at the peak of the first arrival rather than the first break. This 
method is valid when only relative travel times are required, for example, to calculate interval velocities. We use a sliding window of $50 \mathrm{~m}$ length to determine interval velocities along the three azimuths. When calculating seismic interval velocities, the thickness of the interval selected depends on the trade-off between resolution and noise levels. Within each $50 \mathrm{~m}$ window we determine the best linear fit to the travel time picks and calculate the interval velocity from the gradient. Velocity uncertainties are calculated using the 1 standard deviation uncertainty of the linear travel time fit over each $50 \mathrm{~m}$ sliding window. The range of velocities over each window is calculated by perturbing the interval travel time by plus and minus 2 standard deviations to emulate the maximum possible range of travel time intervals. As depths are relative, the error in interval length is negligible. Figure 4 presents interval velocities from the 0,50 and $100 \mathrm{~m}$ offset shots. Table 1 presents mean interval velocities between 380 and $540 \mathrm{~m}$ shots over the three azimuths and offsets out to $100 \mathrm{~m}$. We select the upper limit of this interval to exclude the harmonic noise in the upper half of the ice column and the discontinuity in the P-wave arrival at approximately $300 \mathrm{~m}$ depth. Below $540 \mathrm{~m}$ depth, the sliding window length precludes further measurements. Although the interval velocities between 200 and $300 \mathrm{~m}$ are consistent, the interaction with the harmonic noise leads us to question the reliability, and we do not evaluate this interval any further. To convert from apparent to true velocity we calculate the incidence angle of the wavefront at the vertical fibre optic cable by ray tracing to the centre of the receiver interval with an isotropic velocity model based on measurements at the nearby Korff Ice Rise (Brisbourne et al., 2019; Guest and Kendall, 1993).

The mean velocity of $3984 \pm 218 \mathrm{~m} \mathrm{~s}^{-1}$ is high but comparable to measurements of Booth et al. (2020) in the deepest part of the ice column of Store Glacier, Greenland, and Diez et al. (2015) along the EDML ice core from Kohnen Station, Antarctica (EDML: EPICA Dronning Maud Land; EPICA: European Project for Ice Coring in Antarctica). Although uncertainties are large (Table 1), they are comparable to the uncertainties in VSP measurements at depth in ice of Diez et al. (2015) and Booth et al. (2020). Both of these previous studies attribute the high velocities to a fabric with aligned vertical $c$ axes. A vertical cluster is consistent with the fabric development expected at ice divides using a numerical model (Martin et al., 2009), as well as the measurements of Diez et al. (2015) using both seismic VSP data and crystal orientation fabric (COF) measured in ice cores. Uncertainties in the velocity measurement preclude the interpretation of fabric from depth or azimuthal variation in P-wave velocity. The signal to noise level is too low to derive reliable S-wave velocities.

\subsection{Seismic attenuation}

The spectral ratio method (Bath, 1974) is applied to the direct P-wave arrivals to determine seismic attenuation along ver-
Table 1. Vertical interval velocities measured between 380 and $540 \mathrm{~m}$ depth. Uncertainties are 1 standard deviation.

\begin{tabular}{lrr}
\hline Line & Shot offset $(\mathrm{m})$ & $V_{\text {INT }}\left(\mathrm{m} \mathrm{s}^{-1}\right)$ \\
\hline ST040 & 50 & $3996 \pm 298$ \\
ST040 & 100 & $3983 \pm 107$ \\
ST085 & 50 & $4079 \pm 271$ \\
ST085 & 100 & - \\
ST130 & 0 & $3952 \pm 188$ \\
ST130 & 50 & $3989 \pm 215$ \\
ST130 & 100 & $3902 \pm 171$ \\
\hline Mean & & $3984 \pm 218$ \\
\hline
\end{tabular}

tical propagation paths within the ice column (Fig. 5). The natural logarithm of the spectral ratio is derived as follows:

$\ln \left|\frac{A_{1}(f)}{A_{2}(f)}\right|=$ const. $+\pi \frac{\delta t}{Q} f$

where $f$ is the frequency of the seismic wavelet and $\delta t$ is the measurement travel time interval. The slope of the spectral ratio $m=\pi \frac{\delta t}{Q}$ yields the seismic quality factor, $Q$.

We apply the spectral ratio method across a single depth interval from 380 to $540 \mathrm{~m}$, consistent with the interval velocity measurements. We use the zero-offset shots to analyse vertical raypaths as a strong dependence of attenuation on crystal orientation has previously been demonstrated (Oguro et al., 1982). To aid phase picking, traces are bandpass filtered at $2-140 \mathrm{~Hz}$. Traces are then windowed around the primary P-wave arrivals. DAS measurements of strain rate implicitly average over a gauge length of $10 \mathrm{~m}$ (defined by the DAS hardware). In addition, at SIR, little change is expected in the ice column over a $10 \mathrm{~m}$ depth range. Therefore, to improve the signal to noise ratio, traces are stacked over a $10 \mathrm{~m}$ window at the respective depths. To remove noisy traces and compensate for the discontinuous nature of the wave train, prior to stacking we perform a cross-correlation to evaluate each trace against the central trace of the respective interval. Traces with a correlation coefficient $<0.95$ are discarded, removing $45 \%$ of traces (Fig. $5 \mathrm{a}-\mathrm{c}$ ). To calculate the uncertainty in the gradient measurements the $95 \%$ confidence limits of the stacked traces are used, analysing waveforms at the extremes of this envelope (Fig. 5a, b) to calculate a range of spectral ratios and therefore gradients. In addition, the uncertainty in the gradient fit and travel times $( \pm 1 \mathrm{~ms})$ are used to determine the uncertainty in $Q$. A mean interval $Q$ of $75 \pm 12$ for this lower section of the ice column is measured. The uncertainties are consistent with previous studies that use the spectral ratio method (Dasgupta and Clark, 1998; Peters et al., 2012). The temperature measured over this depth range in the ice column is -20 to $-17^{\circ} \mathrm{C}$ (Mulvaney et al., 2021). 

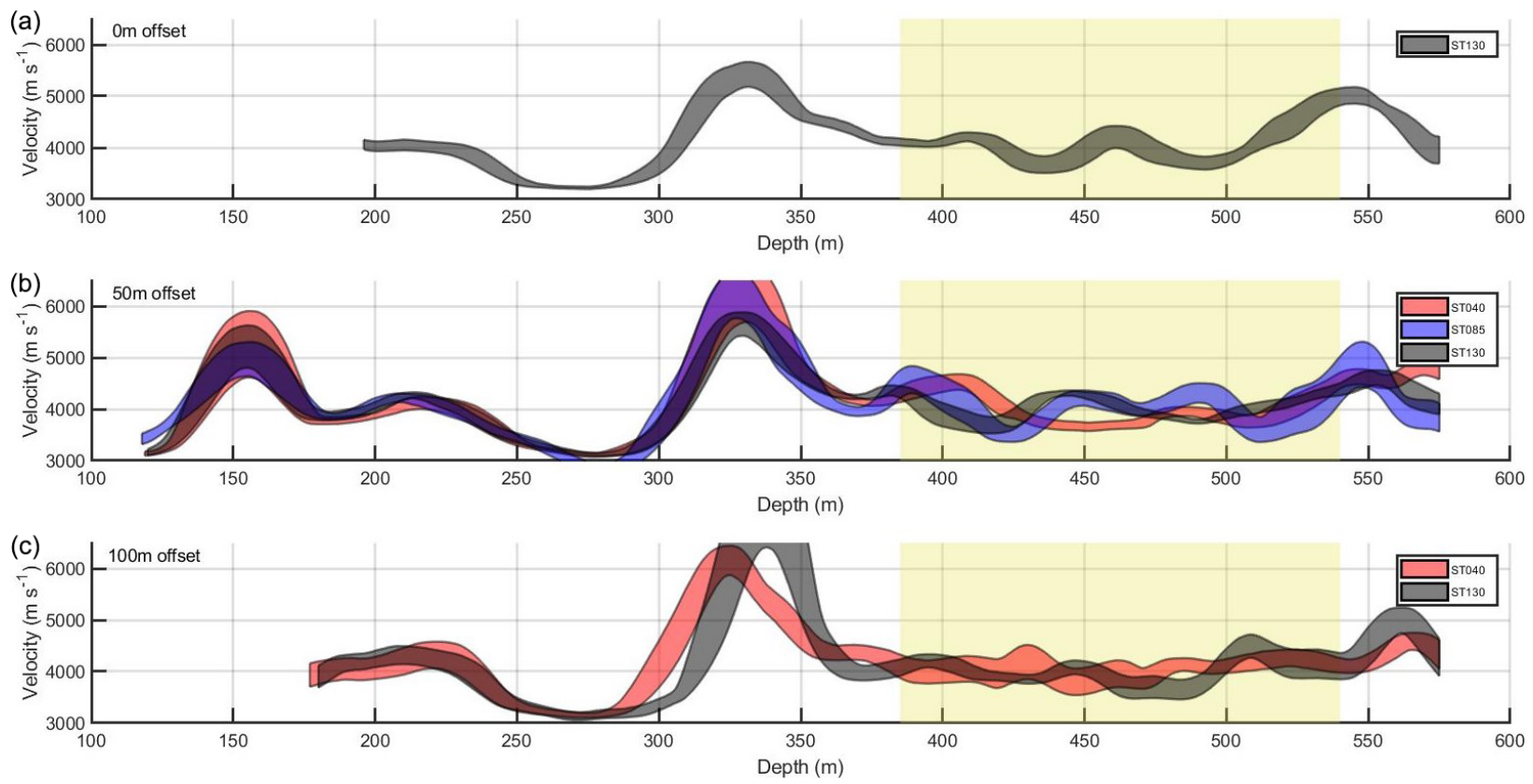

Figure 4. Vertical P-wave velocity from $0 \mathrm{~m}$ (a), $50 \mathrm{~m}$ (b) and $100 \mathrm{~m}$ offset (c) shots calculated using a linear fit to $50 \mathrm{~m}$ sliding windows. Velocities are converted from the apparent velocity assuming incidence angles at the midpoint of the respective sliding window following ray tracing through an isotropic model. The width of the fitted curves represents the velocity uncertainty calculated from the travel time uncertainty over each sliding window. The yellow box represents the depth range over which mean interval velocities are presented in Table 1 (380 to $540 \mathrm{~m}$ depth).
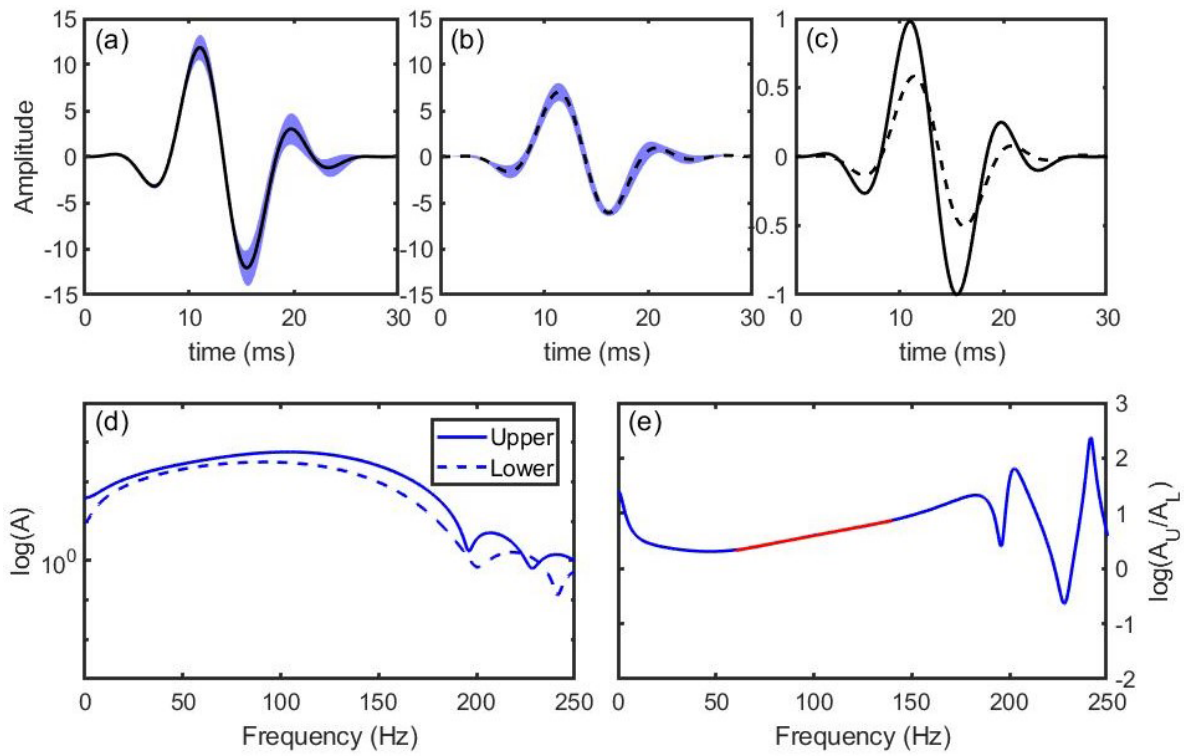

Figure 5. Use of the spectral ratio method to determine seismic attenuation. Traces are stacked around the direct P-wave arrivals over a $10 \mathrm{~m}$ interval. The cross-correlation with the central trace in the respective depth window is calculated, and only traces with a coefficient $>0.95$ are used. (a) Upper stacked trace (380 to $390 \mathrm{~m}$; solid line) and (b) lower stacked trace (530 to $540 \mathrm{~m}$; dashed line), both with $95 \%$ confidence bounds calculated from the summed traces in blue. (c) Upper (solid line) and lower (dashed line) stacked traces with normalised amplitude. (d) Amplitude spectra of the upper and lower stacked waveforms. (e) Log spectral ratio with the frequency range over which the gradient is measured in red $(60-140 \mathrm{~Hz})$. 


\section{Evaluating the potential of DAS VSP for ice column fabric discrimination using synthetic travel times and amplitudes}

Our observations of $\mathrm{P}$ - and $\mathrm{S}$-waves, both direct and reflected and at a range of offsets and azimuths, demonstrate the potential for DAS-type measurements at Antarctic ice rises. We therefore investigate the capacity of DAS measurements to discriminate ice column fabric at ice rises to guide future experiments investigating ice sheet history through fabric evolution (e.g. Brisbourne et al., 2019). We use the software package ATRAK (Guest and Kendall, 1993), based on asymptotic ray theory (Kendall and Thomson, 1989), to calculate travel times and amplitudes of direct P- and S-wave arrivals from a range of offsets and azimuths. We used an isotropic source with identical P, SV and SH amplitudes. An isotropic seismic velocity profile is used in the firn, derived from a previous seismic refraction experiment at Korff Ice Rise (Brisbourne et al., 2019). We test three models of fabric at ice rises, including (1) an isotropic model and (2) a model with an isotropic layer over a layer with a strong cluster fabric at depth. Critically, radar methods with collocated source and receiver are insensitive to vertical cluster (or azimuthally invariant) fabrics, and seismic methods provide an approach to quantify any azimuthally invariant fabric (Brisbourne et al., 2019). (3) The final model is based on the ice rise fabric predicted by Martin et al. (2009) with a girdle fabric in the upper ice column ( 80 to $230 \mathrm{~m}$ depth) and a cluster fabric at depth ( $230 \mathrm{~m}$ to the ice base). The strength of the girdle fabric and fabric depth transition is based on that reported from Korff Ice Rise by Brisbourne et al. (2019). With a vertical cable, DAS is only sensitive to the vertical component of strain. Therefore, we derive amplitudes from the vertical component only. Displacement amplitudes computed with ATRAK are relative only and assume an isotropic source function with perfect receiver coupling.

Figure 6 presents modelled $\mathrm{P}$ - and SV-wave travel times for a shot offset of $400 \mathrm{~m}$ and the vertical component amplitudes for shot offsets of 200 and $400 \mathrm{~m}$ for the three models of fabric. In the isotropic case (Fig. 6a), as expected there is no azimuthal variation in travel time or amplitude. Amplitudes vary with depth, with the relationship dependent on shot offset. This is a result of both raypath geometry due to the strong velocity gradient in the firn and the limitation of the downhole fibre DAS method, which measures only vertical strain rate.

The cluster-only model (Fig. 6b) exhibits no azimuthal variation in travel time or amplitude. However, in comparison with the isotropic case a very strong depth dependence of $\mathrm{SV}$-wave amplitude is observed. The depth of the peak in SVwave amplitude is dependent on the offset of the shot: shots at progressively greater offset produce peaks in SV-wave amplitude at progressively greater depth. This is a result of the focussing of S-wave energy by the strong cluster fabric in what is a homogeneous but anisotropic layer. The depth of the anisotropic layer will also control the depth distribution of amplitudes. This amplitude variation is a diagnostic feature that could be quantified in data acquired with a seismic source designed specifically to produce $\mathrm{S}$-waves, such as that of Lutz et al. (2020). Relatively strong S-wave arrivals are observed in the far offset data from SIR (Fig. 2d), although no attempt is made to quantify amplitude variation due to the low signal to noise level. For the extreme form of this fabric, a single maximum, this focussing produces a triplication or folding in the wavefront which greatly increases the amplitude at depth (results not presented here). Direct observation of a triplication would only be feasible with very high-quality measurements and the strong fabrics and is likely to be beyond the experimental capability (Baird et al., 2017).

The presence of a girdle fabric would in general result in azimuthal variation in travel times. However, in our model the effect on P-wave travel times is small (Fig. 6c). For example, the azimuthal variation in $\mathrm{P}$-wave travel times is less than $4 \mathrm{~ms}$ with either a 200 or $400 \mathrm{~m}$ source offset. At $200 \mathrm{~m}$ offset the azimuthal variation in SV-wave travel times is again small, at around $4 \mathrm{~ms}$. However, with a source offset of $400 \mathrm{~m}$, we see an azimuthal variation in SV-wave travel time of over $10 \mathrm{~ms}$, which is likely above the measurement uncertainty with high-quality data and therefore a diagnostic parameter. In the same model, SV-wave amplitudes vary with azimuth by up to $50 \%$ at $450 \mathrm{~m}$ depth and are therefore a robust indicator of fabric if reliable amplitude measurements are available. The azimuthal variation in amplitudes displays maxima at $90^{\circ}$ intervals, i.e. a four-fold symmetry. There is also a strong depth dependence of the amplitude maxima, which increases with increasing shot offset. Depending on the fabric geometry, variations in travel times and amplitudes with depth and azimuth are diagnostic features and highlight the viability of the DAS method to constrain englacial fabric.

In Fig. 7 we present synthetic VSP gathers for the two end-member models presented in Fig. 6a and c respectively. We use P, SV and SH travel times and amplitudes from the anisotropic ray tracing convolved with a $100 \mathrm{~Hz}$ centre frequency synthetic wavelet and its Hilbert transform. These gathers display the features observed in Fig. 6, such as the higher amplitude $\mathrm{S}$-waves at depth in the isotropic model (Fig. 7a), azimuthal variation in S-wave amplitude (Fig. 7b) and a peak in S-wave amplitude at $450 \mathrm{~m}$ depth with a $400 \mathrm{~m}$ offset source (Fig. 7b). Figure 7c presents details of the Swave arrival at 250 to $350 \mathrm{~m}$ depth in the anisotropic model. The synthetic results indicate that, despite the DAS VSP method measuring only the vertical component of the strain rate, along the $45^{\circ}$ orientation in the fully anisotropic model we would observe split $\mathrm{S}$-waves beyond $280 \mathrm{~m}$ using a $400 \mathrm{~m}$ offset source. This phenomenon, shear wave splitting, is a key diagnostic method for quantifying anisotropy using the seismic method (Savage, 1999). In this case, the later arriving S-wave originates from a horizontally polarised (SH) source. The girdle fabric must therefore impart a rotation of the waveform resulting in a vertical component of particle 

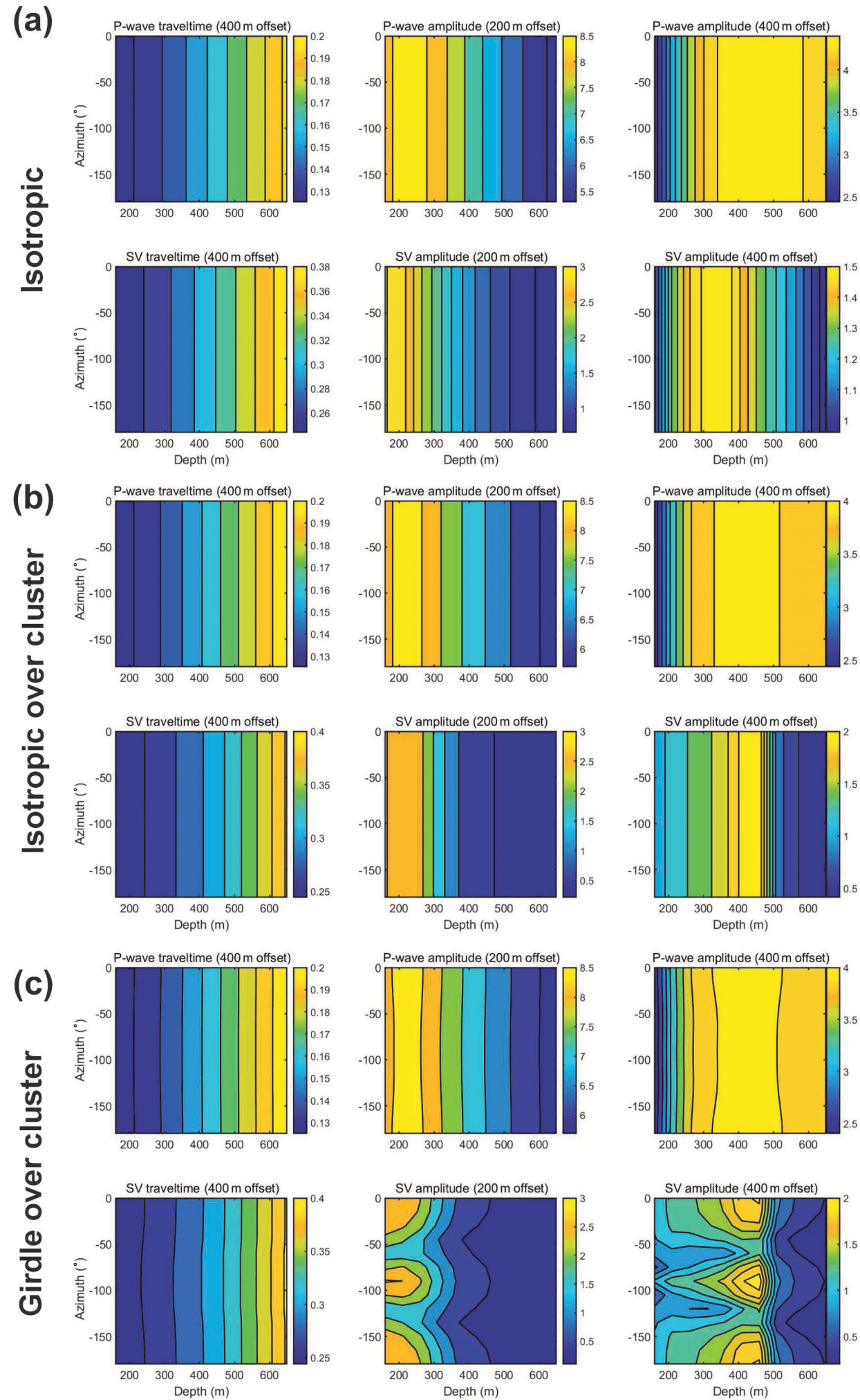

Figure 6. Modelled P-wave and S-wave travel time (seconds) and vertical amplitude variation with depth and azimuth: (a) isotropic, (b) isotropic with cluster fabric below $230 \mathrm{~m}$ and (c) theoretical steady-state ice divide fabric of girdle above strong cluster (Martin et al., 2009). Firn is isotropic in all models, and when present, the transition to cluster fabric is at $230 \mathrm{~m}$ depth. Amplitudes are calculated using the vertical component, consistent with the DAS VSP method. 
(a) Isotropic
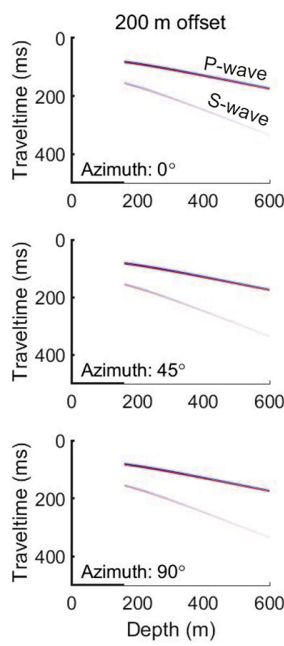

(b) Girdle over cluster
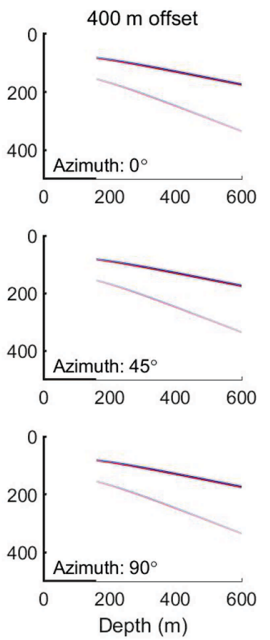
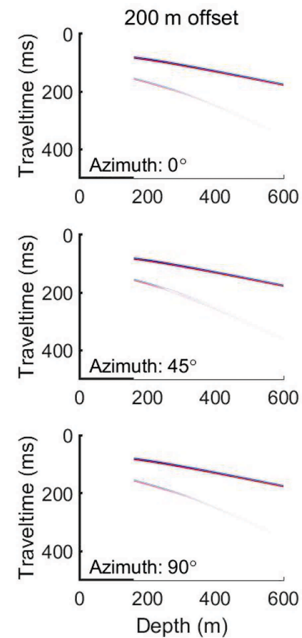
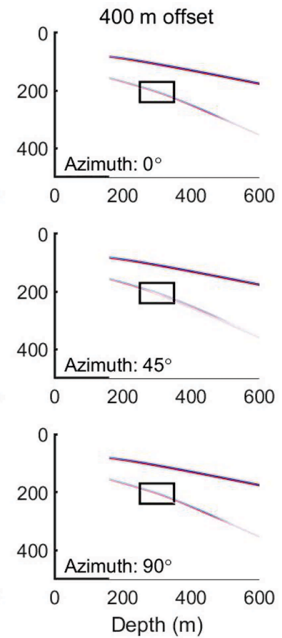

(c) Detail from b
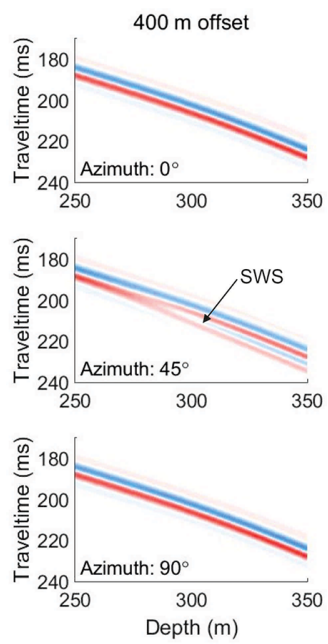

Figure 7. Synthetic VSP gathers at shot offsets of 200 and $400 \mathrm{~m}$ along three azimuths with $45^{\circ}$ rotation. (a) Isotropic velocity model and (b) theoretical steady-state ice divide fabric of girdle above strong cluster (Martin et al., 2009). Black rectangles highlight the range of arrivals presented in detail in (c). (c) Detail of S-wave arrivals at $400 \mathrm{~m}$ offset in the windows highlighted by the black rectangle in (b). S-wave arrival showing shear wave splitting (labelled SWS) along the $45^{\circ}$ azimuth. Firn is isotropic in all models, and when present, the transition to cluster fabric is at $230 \mathrm{~m}$ depth. Amplitudes are calculated using the vertical component, consistent with the DAS VSP method. All sample values are normalised to the maximum value of both models. The anisotropic case highlights peaks in the S-wave amplitude at around $450 \mathrm{~m}$ with a $400 \mathrm{~m}$ shot offset. This feature is not observed in the isotropic case. Azimuthal variation in peak S-wave amplitude is also present but subtle.

motion at the borehole. We see no reliable indication of shear wave splitting in our data from SIR. This modelling result is reliant on an isotropic source with identical $\mathrm{P}, \mathrm{SV}$ and $\mathrm{SH}$ amplitudes. Whether it is possible to generate a seismic source that satisfies these requirements warrants further investigation. In subsequent studies, if shear wave splitting is apparent in the data, it will be pertinent to extend plots like those in Fig. 6 to include the $\mathrm{SH}$ amplitudes and travel times.

\section{Discussion}

Measurements of englacial fabric at Antarctic ice rises have the potential to help constrain recent ice sheet history. DAS VSP data and modelling results presented here highlight the potential of the method to improve our understanding of englacial fabric and therefore recent ice flow history.

Seismic velocities measured in the lower half of the ice column at SIR are high and indicate the likely presence of a strong vertical cluster fabric, consistent with models of fabric formation at ice rises. Observed relatively high amplitude Swaves from far offset shots are also consistent with the presence of englacial fabric. Uncertainties are however too high to establish the depth distribution or azimuthal symmetry of the anisotropy. A cluster fabric within the lower section of the ice column is consistent with ongoing ice divide flow and fabric formation mechanisms (Martin et al., 2009). The time required to form characteristic fabrics at ice divides is a function of the accumulation rate and ice thickness, and as such it varies widely. Stable flow over sufficient time is required to form the characteristic fabric. However, the low strain rate at ice rises also allows remnant fabric from a previous flow regime to persist (Brisbourne et al., 2019). The presence of a cluster fabric at depth is therefore not a conclusive indicator of long-term stable flow. Further data are required to investigate the presence of azimuthally variant fabric, for example, that may form under different flow regimes. When more reliable measurements are available, the conversion of apparent to true velocity will require an estimate of fabric to account for velocity variation; the deviation of the raypath from the vertical will be a function of both fabric and sourcereceiver geometry. A correction will be required to account for the fabric-induced difference in velocity between the raypath and the vertical. This is likely best posed as an inversion problem.

Our measured value of $Q$ is low, indicating higher attenuation than previous field measurements in polar ice at similar temperatures, e.g. $Q=400-670$ at -14 to $-25^{\circ} \mathrm{C}$ (Bentley, 1971) and $Q=130-355$ at -15 to $-22^{\circ} \mathrm{C}$ (Peters et al., 2012). By invoking transformations to account for measurement frequency, impurity uptake from the mother solution and conversion from flexural vibration to acoustic seismic P-waves, Bentley and Kohnen (1976) demonstrated consistency between field measurements of seismic attenuation and the laboratory measurements of Kuroiwa (1964). However, the same laboratory measurements highlight the sensitivity of seismic attenuation to temperature, impurity concentration and signal frequency. An approximately exponential varia- 
tion in attenuation occurs at temperatures close to the melting point (above $-30^{\circ} \mathrm{C}$ ) across all frequencies. Similarly, samples of ice from Antarctica and Greenland exhibit different behaviour to laboratory-generated samples in the temperature range -20 to $-10^{\circ} \mathrm{C}$. Laboratory measurements of internal friction at 4 to $9 \mathrm{~Hz}$ on the Mizuho ice core (Nakamura and Abe, 1978) also highlight sensitivity to temperature at the melting point, and, in contrast to the measurements of Kuroiwa (1964), high degrees of internal friction are observed, equivalent to $Q$ values as low as 10 .

It is important to recognise that a number of mechanisms cause attenuation. Field-derived measurements provide an estimate of effective $Q$, the sum of intrinsic $Q$ (e.g. material properties) and apparent $Q$ (e.g. scattering). Decoupling the effects of intrinsic absorption from scattering (perhaps due to impurities or variations in ice crystal size or fabric) will be difficult without further information (e.g. derived from core). For example, Kuroiwa (1964) highlights the significance of grain boundaries and impurities in polycrystalline ice, which results in sensitivity to temperature close to the melting point. Similarly, using the flexural vibration method, Oguro et al. (1982) demonstrated that internal friction varies by up to a factor of 5 depending on the orientation with respect to the $c$ axis of a single ice crystal. Additional in situ measurements are therefore required to understand better these sensitivities. This requirement is highlighted by the microstructural analysis of the EDML ice core. There, grain size generally increases with depth but is strongly affected by the impurity content of ice from different climatic stages resulting in a step change in grain size at depth (Weikusat et al., 2017), highlighting the shortcomings of attenuation profiles based on incomplete parameterisation.

Our measurements are unusual in that in situ measurements of temperature across the entire ice column are available: most seismic attenuation measurements acquired to date are not coincident with a measured profile of englacial temperature or physical properties of the ice. Furthermore, at SIR, the ice core will allow for measurements of impurity levels and potentially grain size, providing context to our field measurements. For example, mean $\mathrm{NaCl}$ levels in the SIR ice core are low (Robert Mulvaney, personal communication, 2020), with concentrations below the lowest levels tested by Kuroiwa (1964), approximating pure ice for these purposes.

Unlike the DAS VSP observations of Booth et al. (2020), when direct P-wave spectra are consistent over a range of depths, energy loss with depth is apparent in our observations (Fig. 5c, d). Although the spectral ratio analysis method demonstrates that our attenuation measurement is robust, we cannot rule out the influence of the fibre optic cable hanging in the borehole on these measurements, potentially resulting in a form of signal amplitude reduction unrelated to ice properties. For example, is the uniformity of the coupling or behaviour of the cable influenced by the difference in hydrostatic head of drilling fluid above the sampled range? We therefore regard the signal loss as a robust observation but advocate further experiments to determine the cause of the high degree of attenuation.

Our ray tracing results indicate that englacial fabric at ice rises will likely lead to diagnostic features in DAS VSP data, such as azimuthal variation in travel times and amplitudes. We also observe shear wave splitting in the synthetic data caused by the girdle fabric. In addition to the fabric geometry, these modelling results are dependent on the velocity profile, seismic source geometry and the acquisition geometry, and they will therefore act as a guide in the design of future experiments.

\section{Recommendations}

We combine our field experience, data analysis and modelling results to make a number of recommendations to assist in future experiment design using DAS technology in polar borehole settings.

With respect to the cable deployment in the borehole, data quality is controlled by the coupling of the cable to the ice and the suppression of vibrations along the cable. Unlike locations with high strain-rate or temperate ice, the closure of boreholes at Antarctic ice rises will take a number of years. Therefore, in the time available, achieving a frozen-in cable to ensure both coupling to the ice and the suppression of harmonic vibrations is not always possible. In our data, below $350 \mathrm{~m}$ depth, we observe reflected P-waves and their surface-multiples, implying that drilling fluid in the lower part of the borehole is providing good coupling to the ice. The harmonic noise is also suppressed over these depths. Therefore, where borehole closure will not occur naturally in a reasonable timeframe, the seismic experiment should be undertaken with drilling fluid filling the entire borehole (below the firn), i.e. prior to recovery of the drilling fluid. In addition, as variation in seismic amplitude is a key diagnostic for constraining fabric geometry, consistent coupling to the borehole is critical. Whether fluid provides this consistency remains untested. An alternative solution may be backfilling the borehole with water to accelerate freeze-in.

Although data acquired with the hammer and plate seismic source demonstrate the feasibility of the DAS method and have been demonstrated as viable when the fibre optic cable is well-coupled (Booth et al., 2020), a more energetic source (e.g. explosives) would increase the signal to noise ratio and improve the analysis capability beyond that demonstrated here.

Using a geophone and data logger located adjacent to the hammer plate proved to be adequate for estimating source time in this experiment. However, improved timing accuracy is possible with either direct trigger of the DAS recording unit or higher sampling rate of the geophone adjacent to the source. Alternatively, if using an explosive source, we rec- 
ommend a GPS-synchronised trigger in parallel with GPS timing on the interrogator.

A ruggedised interrogator unit would reduce complexity of the acquisition process (e.g. tolerance to temperature, ruggedised user interface, tolerance to unplanned power outage with automatic restart). An interrogator with low power consumption, or a substantial solar power system, would enable the use of battery power and thus remove the noise source of the generator. In this case, if the interrogator unit requires mains power ( 110 or $240 \mathrm{~V} \mathrm{AC}$ ), then an inverter is required, the use of which needs to be carefully managed in polar environments to protect both the user and the instrument.

This experiment utilised a multi-mode fibre cable deployed specifically for DTS measurements. However, it is now standard to deploy cables with both multi-mode and single-mode fibres, and this should be utilised for all future deployments. Optical fibre with a helical structure may extend measurements beyond one-dimensional longitudinal strain (Kuvshinov, 2015).

Modelling of the seismic response to likely fabric configurations will optimise field acquisition. Although amplitude variation is a key diagnostic in the scenarios tested here, strong girdle fabrics will also result in measurable travel time variation.

Modelling results for likely ice rise fabric indicate that Swave travel time and amplitude variations are key diagnostics with the seismic method. Reliance on P-wave travel time and amplitude variation will limit the capacity of the observations to constrain fabric. As such, a reliable $S$-wave seismic source is essential (e.g. Lutz et al., 2020). To what degree an explosive source will be effective remains to be tested.

Additional data, such as polarimetric radar measurements or a three-component geophone surface array, may improve the uniqueness of any interpretation. The deployment of additional fibre optic cable along the surface will complement downhole observations at little logistical overhead. However, measurements using surface-deployed cable will be limited to horizontal longitudinal strain rate, and further modelling will be required to explore the benefit of this additional information in such scenarios. With a single fibre optic cable for both downhole and surface measurements, only a single interrogator unit is necessary.

\section{Conclusions}

We have demonstrated the feasibility and potential of DAS measurements in Antarctic settings using existing infrastructure. This presents opportunities for relatively low-cost and logistically light experiments, both adding value to existing studies and opening opportunities for continent-wide experiments at relatively low risk. We have presented results from a walkaway VSP experiment acquired at SIR. Estimates of seismic velocity $\left(3984 \pm 218 \mathrm{~m} \mathrm{~s}^{-1}\right)$ in the lower section of the ice column are consistent with a cluster fabric. Relatively high S-wave amplitudes from far-offset shots are also consistent with the presence of fabric. Estimates of $Q$ in the same interval $(75 \pm 12)$ are lower than previous estimates of attenuation in ice. Our data lack the signal strength required to allow for a more detailed interpretation of the structure at SIR. However, observations of direct and reflected seismic waves from a low-energy hammer source at a range of offsets and azimuths underscore the potential of the DAS method to investigate the englacial and basal structures in similar settings. Modelling the effect of likely ice fabric geometries on P- and $\mathrm{S}$-wave travel times and amplitudes demonstrates the potential for this method to identify and discriminate ice fabric at ice rises. The results of this pilot study present an opportunity to improve the design of future experiments, and we make a number of recommendations related to acquisition design, instrumentation and field methodology.

Data availability. Data are available at the Polar Data Centre for public access (Brisbourne and Kendall, 2021).

Author contributions. AMB and MK designed and led the experiment with support from SKK and AMS. MK conducted data acquisition with support from AMB and SKK. AMB undertook data analysis with assistance from MK, TSH and SKK. AMB wrote the manuscript with contributions from all others.

Competing interests. The authors declare that they have no conflict of interest.

Disclaimer. Publisher's note: Copernicus Publications remains neutral with regard to jurisdictional claims in published maps and institutional affiliations.

Acknowledgements. We are grateful to Anne Flink, BAS Operations and Rothera Station personnel who supported this experiment. Athena Chalari and Andy Clarke at Silixa Ltd loaned equipment, assisted with planning and provided technical support. Fieldwork was undertaken as part of the BEAMISH Project (NERC AFI award numbers NE/G014159/1). The SIR borehole and fibre optic cable are part of the University of Cambridge WACSWAIN Project (EU Horizon 2020 agreement no. 742224). We thank the Computational Infrastructure for Geodynamics (http://geodynamics.org, last access: May 2020) which is funded by the National Science Foundation under awards EAR-0949446 and EAR-1550901.

Financial support. This research has been supported by the Natural Environment Research Council (grant nos. NE/G014159/1 and CASS-166) and by the DigiMon project (project no. 299622), which is part of Accelerating CCS Technologies (ACT) programme. 
Review statement. This paper was edited by Nanna Bjørnholt Karlsson and reviewed by Huw Horgan and one anonymous referee.

\section{References}

Alley, R. B.: Fabrics in polar ice sheets: development and prediction, Science, 240, 493-495, https://doi.org/10.1126/science.240.4851.493, 1988.

Azuma, N. and Higashi, A.: Formation Processes of Ice Fabric Pattern in Ice Sheets, Ann. Glaciol., 6, 130-134, https://doi.org/10.3189/1985AoG6-1-130-134, 1985.

Azuma, N., Wang, Y., Mori, K., Narita, H., Hondoh, T., Shoji, H., and Watanabe, O.: Textures and fabrics in the Dome F (Antarctica) ice core, Ann. Glaciol., 29, 163-168, 1999.

Baird, A. F., Kendall, J. M., Fisher, Q. J., and Budge, J.: The Role of Texture, Cracks, and Fractures in Highly Anisotropic Shales, J. Geophys. Res.-Sol. Ea., 122, 1034110351, https://doi.org/10.1002/2017jb014710, 2017.

Bargmann, S., Seddik, H., and Greve, R.: Computational modeling of flow-induced anisotropy of polar ice for the EDML deep drilling site, Antarctica: The effect of rotation recrystallization and grain boundary migration, Int. J. Numer. Anal. Met., 36, 892-917, https://doi.org/10.1002/nag.1034, 2012.

Barletta, V. R., Bevis, M., Smith, B. E., Wilson, T., Brown, A., Bordoni, A., Willis, M., Khan, S. A., Rovira-Navarro, M., Dalziel, I., Smalley, R., Kendrick, E., Konfal, S., Caccamise, D. J., Aster, R. C., Nyblade, A., and Wiens, D. A.: Observed rapid bedrock uplift in Amundsen Sea Embayment promotes ice-sheet stability, Science, 360, 1335-1339, https://doi.org/10.1126/science.aao1447, 2018.

Bath, M.: Spectral analysis in geophysics, in: Developments in Solid Earth Geophysics, Elsevier, Amsterdam, 415 pp., 1974.

Bentley, C. R.: Seismic Evidence for Moraine within the Basal Antarctic Ice Sheet, in: Antarctic snow and ice studies II, edited by: Crary, A. P., American Geophysical Union, Washington, DC, 89-129, https://doi.org/10.1029/AR016p0089, 1971.

Bentley, C. R.: Seismic-Wave Velocities in Anisotropic Ice - Comparison of Measured and Calculated Values in and around Deep Drill Hole at Byrd Station, Antarctica, J. Geophys. Res., 77, 4406, https://doi.org/10.1029/Jb077i023p04406, 1972.

Bentley, C. R. and Kohnen, H.: Seismic refraction measurements of internal friction in Antarctic ice, J. Geophys. Res., 81, 15191526, https://doi.org/10.1029/JB081i008p01519, 1976.

Blankenship, D. D. and Bentley, C. R.: The crystalline fabric of polar ice sheets inferred from seismic anisotropy, IAHS Publ., 170, 17-28, 1987.

Booth, A. D., Christoffersen, P., Schoonman, C., Clarke, A., Hubbard, B., Law, R., Doyle, S. H., Chudley, T. R., and Chalari, A.: Distributed Acoustic Sensing of Seismic Properties in a Borehole Drilled on a Fast-Flowing Greenlandic Outlet Glacier, Geophys. Res. Lett., 47, e2020GL088148, https://doi.org/10.1029/2020gl088148, 2020.

Bradley, S. L., Hindmarsh, R. C. A., Whitehouse, P. L., Bentley, M. J., and King, M. A.: Low post-glacial rebound rates in the Weddell Sea due to Late Holocene ice-sheet readvance, Earth Planet. Sc. Lett., 413, 79-89, https://doi.org/10.1016/j.epsl.2014.12.039, 2015 .
Brisbourne, A. M. and Kendall, K. M.: Downhole distributed acoustic seismic profiles at SkyTrain Ice Rise, West Antarctica, January 2020 (Version 1.0) [Data set], UK Polar Data Centre, Natural Environment Research Council, UK Research \& Innovation, https://doi.org/10.5285/99F0D269-D8FA-48E0-89E6358486D82330, 2021.

Brisbourne, A. M., Martín, C., Smith, A. M., Baird, A. F., Kendall, J. M., and Kingslake, J.: Constraining Recent Ice Flow History at Korff Ice Rise, West Antarctica, Using Radar and Seismic Measurements of Ice Fabric, J. Geophys. Res.-Earth, 124, 175-194, https://doi.org/10.1029/2018jf004776, 2019.

Conway, H., Hall, B. L., Denton, G. H., Gades, A. M., and Waddington, E. D.: Past and future grounding-line retreat of the West Antarctic Ice Sheet, Science, 286, 280-283, https://doi.org/10.1126/science.286.5438.280, 1999.

Dasgupta, R. and Clark, R. A.: Estimation of $Q$ from surface seismic reflection data, Geophysics, 63, 2120-2128, https://doi.org/10.1190/1.1444505, 1998.

Dean, T., Cuny, T., and Hartog, A. H.: The effect of gauge length on axially incident P-waves measured using fibre optic distributed vibration sensing, Geophys. Prospect., 65, 184-193, https://doi.org/10.1111/1365-2478.12419, 2017.

Diez, A., Eisen, O., Hofstede, C., Lambrecht, A., Mayer, C., Miller, H., Steinhage, D., Binder, T., and Weikusat, I.: Seismic wave propagation in anisotropic ice - Part 2: Effects of crystal anisotropy in geophysical data, The Cryosphere, 9, 385-398, https://doi.org/10.5194/tc-9-385-2015, 2015.

Doake, C. S. M., Corr, H. F. J., and Jenkins, A.: Polarisation of radio waves transmitted through Antarctic ice shelves., Ann. Glaciol., 34, 165-170, 2002.

Durand, G., Gillet-Chaulet, F., Svensson, A., Gagliardini, O., Kipfstuhl, S., Meyssonnier, J., Parrenin, F., Duval, P., and Dahl-Jensen, D.: Change in ice rheology during climate variations - implications for ice flow modelling and dating of the EPICA Dome C core, Clim. Past, 3, 155-167, https://doi.org/10.5194/cp-3-1552007, 2007.

Duval, P., Ashby, M., and Anderman, I.: Rate-controlling processes in the creep of polycrystalline ice, J. Phys. Chem., 87, 40664074, 1983.

Fujita, S., Maeno, H., and Matsuoka, K.: Radio-wave depolarization and scattering within ice sheets: a matrix-based model to link radar and ice-core measurements and its application, J. Glaciol., 52, 407-424, https://doi.org/10.3189/172756506781828548, 2006.

Griffiths, L. J., Smolka, F. R., and Trembly, L. D.: Adaptive Deconvolution: A New Technique for Processing Time-Varying Seismic Data, Geophysics, 42, 742-759, https://doi.org/10.1190/1.1440743, 1977.

Guest, W. S. and Kendall, J. M.: Modelling seismic waveforms in anisotropic inhomogeneous media using ray and Maslov asymptotic theory: application to exploration seismology, Can. J. Explor. Geophys., 29, 78-92, 1993.

Hargreaves, N. D.: The polarization of radio signals in the radio echo sounding of ice sheets, J. Phys. D, 10, 1285-1304, https://doi.org/10.1088/0022-3727/10/9/012, 1977.

Hartog, A. H.: An introduction to distributed optical fibre sensors, CRC Press/Taylor and Francis, Boca Raton, Florida, 2017.

Hillenbrand, C. D., Bentley, M. J., Stolldorf, T. D., Hein, A. S., Kuhn, G., Graham, A. G. C., Fogwill, C. J., Kristoffersen, Y., 
Smith, J. A., Anderson, J. B., Larter, R. D., Melles, M., Hodgson, D. A., Mulvaney, R., and Sugden, D. E.: Reconstruction of changes in the Weddell Sea sector of the Antarctic Ice Sheet since the Last Glacial Maximum, Quaternary Sci. Rev., 100, 111-136, https://doi.org/10.1016/j.quascirev.2013.07.020, 2014.

Horgan, H. J., Anandakrishnan, S., Alley, R. B., Peters, L. E., Tsoflias, G. P., Voigt, D. E., and Winberry, J. P.: Complex fabric development revealed by englacial seismic reflectivity: Jakobshavn Isbr ae, Greenland, Geophys. Res. Lett., 35, L10501, https://doi.org/10.1029/2008g1033712, 2008.

Horgan, H. J., Anandakrishnan, S., Alley, R. B., Burkett, P. G., and Peters, L. E.: Englacial seismic reflectivity: imaging crystalorientation fabric in West Antarctica, J. Glaciol., 57, 639-650, 2011.

Hubbard, B., Binley, A., Slater, L., Middleton, R., and Kulessa, B.: Inter-borehole electrical resistivity imaging of englacial drainage, J. Glaciol., 44, 429-435, 1998.

Hubbard, B., Philippe, M., Pattyn, F., Drews, R., Young, T. J., Bruyninx, C., Bergeot, N., Fjøsne, K., and Tison, J.-L.: High-resolution distributed vertical strain and velocity from repeat borehole logging by optical televiewer: Derwael Ice Rise, Antarctica, J. Glaciol., 66, 523-529, https://doi.org/10.1017/jog.2020.18, 2020.

IPCC: Climate Change 2013: The Physical Science Basis. Contribution of Working Group I to the Fifth Assessment Report of the Intergovernmental Panel on Climate Change, Cambridge University Press, Cambridge, United Kingdom and New York, NY, USA, 1535 pp., 2013.

Kendall, J.-M. and Thomson, C. J.: A comment on the form of the geometrical spreading equations, with some numerical examples of seismic ray tracing in inhomogeneous, anisotropic media, Geophys. J. Int., 99, 401-413, https://doi.org/10.1111/j.1365246X.1989.tb01697.x, 1989.

Kingslake, J., Martin, C., Arthern, R. J., Corr, H. F. J., and King, E. C.: Ice-flow reorganization in West Antarctica $2.5 \mathrm{kyr}$ ago dated using radar-derived englacial flow velocities, Geophys. Res. Lett., 43, 9103-9112, https://doi.org/10.1002/2016gl070278, 2016.

Kingslake, J., Scherer, R. P., Albrecht, T., Coenen, J., Powell, R. D., Reese, R., Stansell, N. D., Tulaczyk, S., Wearing, M. G., and Whitehouse, P. L.: Extensive retreat and re-advance of the West Antarctic Ice Sheet during the Holocene, Nature, 558, 430-434, https://doi.org/10.1038/s41586-018-0208-x, 2018.

Kuroiwa, D.: Internal Friction of Ice. I; The Internal Friction of $\mathrm{H}_{2} \mathrm{O}$ and $\mathrm{D}_{2} \mathrm{O}$ Ice, and the Influence of Chemical Impurities on Mechanical Damping, Contributions from the Institute of Low Temperature Science, 18, 1-37, 1964.

Kuvshinov, B. N.: Interaction of helically wound fibre-optic cables with plane seismic waves, Geophys. Prospect., 64, 671-688, https://doi.org/10.1111/1365-2478.12303, 2015.

Larour, E., Seroussi, H., Adhikari, S., Ivins, E., Caron, L., Morlighem, M., and Schlegel, N.: Slowdown in Antarctic mass loss from solid Earth and sea-level feedbacks, Science, 364, eaav7908, https://doi.org/10.1126/science.aav7908, 2019.

Lipenkov, V. Y., Barkov, N. I., Duval, P., and Pimienta, P.: Crystalline Texture of the 2083-M Ice Core at Vostok Station, Antarctica, J. Glaciol., 35, 392-398, 1989.

Lutz, F., Eccles, J., Prior, D. J., Craw, L., Fan, S., Hulbe, C., Forbes, M., Still, H., Pyne, A., and Mandeno, D.: Constraining Ice Shelf
Anisotropy Using Shear Wave Splitting Measurements from Active-Source Borehole Seismics, J. Geophys. Res.-Earth, 125, e2020JF005707, https://doi.org/10.1029/2020JF005707, 2020.

Martin, C., Hindmarsh, R. C. A., and Navarro, F. J.: Dating ice flow change near the flow divide at Roosevelt Island, Antarctica, by using a thermomechanical model to predict radar stratigraphy, J. Geophys. Res.-Earth, 111, F01011, https://doi.org/10.1029/2005jf000326, 2006.

Martin, C., Gudmundsson, G. H., Pritchard, H. D., and Gagliardini, O.: On the effects of anisotropic rheology on ice flow, internal structure, and the age-depth relationship at ice divides, J. Geophys. Res.-Earth, 114, F04001, https://doi.org/10.1029/2008jf001204, 2009.

Matsuoka, K., Hindmarsh, R. C. A., Moholdt, G., Bentley, M. J., Pritchard, H. D., Brown, J., Conway, H., Drews, R., Durand, G., Goldberg, D., Hattermann, T., Kingslake, J., Lenaerts, J. T. M., Martin, C., Mulvaney, R., Nicholls, K. W., Pattyn, F., Ross, N., Scambos, T., and Whitehouse, P. L.: Antarctic ice rises and rumples: Their properties and significance for icesheet dynamics and evolution, Earth-Sci. Rev., 150, 724-745, https://doi.org/10.1016/j.earscirev.2015.09.004, 2015.

Mercer, J. H.: West Antarctic ice sheet and $\mathrm{CO}_{2}$ greenhouse effect: a threat of disaster, Nature, 271, 321-325, 1978.

Montagnat, M., Buiron, D., Arnaud, L., Broquet, A., Schlitz, P., Jacob, R., and Kipfstuhl, S.: Measurements and numerical simulation of fabric evolution along the Tabs Dome ice core, Antarctica, Earth Planet. Sc. Lett., 357, 168-178, https://doi.org/10.1016/j.eps1.2012.09.025, 2012.

Mulvaney, R., Rix, J., Polfrey, S., Grieman, M., Martìn, C., Nehrbass-Ahles, C., Rowell, I., Tuckwell, R., and Wolff, E.: Ice drilling on Skytrain Ice Rise and Sherman Island, Antarctica, Ann. Glaciol., 1-13, https://doi.org/10.1017/aog.2021.7, online first, 2021.

Nakamura, T. and Abe, O.: Internal friction of Antarctic Mizuho ice cores at low frequency, Mem. Natl. Inst. Polar Res. (Jpn.), 10, 102-113, 1978.

Nereson, N. A., Raymond, C. F., Waddington, E. D., and Jacobel, R. W.: Recent migration of Siple Dome ice divide, West Antarctica, J. Glaciol., 44, 643-652, 1998.

Obbard, R. W., Cassano, T., Aho, K., Troderman, G., and Baker, I.: Using borehole logging and electron backscatter diffraction to orient an ice core from Upper Fremont Glacier, Wyoming, USA, J. Glaciol., 57, 832-840, https://doi.org/10.3189/002214311798043762, 2011.

Oguro, M., Hatano, K., and Kato, S.: Orientation dependence of internal friction in artificial single crystals of ice, Cold Reg. Sci. Technol., 6, 29-35, https://doi.org/10.1016/0165232X(82)90042-8, 1982.

Peters, L. E., Anandakrishnan, S., Alley, R. B., and Voigt, D. E.: Seismic attenuation in glacial ice: A proxy for englacial temperature, J. Geophys. Res.-Earth, 117, F02008, https://doi.org/10.1029/2011jf002201, 2012.

Raymond, C. F.: Flow in a transverse section of Athabasca Glacier, Alberta, Canada, J. Glaciol., 10, 55-84, 1971.

Raymond, C. F.: Deformation in the vicinity of ice divides, J. Glaciol., 29, 357-373, 1983.

Rignot, E., Mouginot, J., and Scheuchl, B.: Ice Flow of the Antarctic Ice Sheet, Science, 333, 1427-1430, https://doi.org/10.1126/science.1208336, 2011. 
Rignot, E., Mouginot, J., Scheuchl, B., van den Broeke, M., van Wessem, M. J., and Morlighem, M.: Four decades of Antarctic Ice Sheet mass balance from 1979-2017, P. Natl. Acad. Sci., 116, 1095-1103, https://doi.org/10.1073/pnas.1812883116, 2019.

Rix, J., Mulvaney, R., Hong, J., and Ashurst, D. A. N.: Development of the British Antarctic Survey Rapid Access Isotope Drill, J. Glaciol., 65, 288-298, https://doi.org/10.1017/jog.2019.9, 2019.

Roberson, S. and Hubbard, B.: Application of borehole optical televiewing to investigating the $3-\mathrm{D}$ structure of glaciers: implications for the formation of longitudinal debris ridges, midre Lovénbreen, Svalbard, J. Glaciol., 56, 143-156, 2010.

Ross, N., Bingham, R. G., Corr, H. F. J., Ferraccioli, F., Jordan, T. A., Le Brocq, A., Rippin, D. M., Young, D., Blankenship, D. D., and Siegert, M. J.: Steep reverse bed slope at the grounding line of the Weddell Sea sector in West Antarctica, Nat. Geosci., 5, 393-396, https://doi.org/10.1038/ngeo1468, 2012.

Savage, M. K.: Seismic anisotropy and mantle deformation: What have we learned from shear wave splitting?, Rev. Geophys., 37, 65-106, https://doi.org/10.1029/98rg02075, 1999.

Scambos, T. A., Haran, T. M., Fahnestock, M. A., Painter, T. H., and Bohlander, J.: MODIS-based Mosaic of Antarctica (MOA) data sets: Continent-wide surface morphology and snow grain size, Remote Sens. Environ., 111, 242-257, https://doi.org/10.1016/j.rse.2006.12.020, 2007.

Shepherd, A., Ivins, E., Rignot, E., Smith, B., van den Broeke, M., Velicogna, I., Whitehouse, P., Briggs, K., Joughin, I., Krinner, G., Nowicki, S., Payne, T., Scambos, T., Schlegel, N., A, G., Agosta, C., Ahlstrøm, A., Babonis, G., Barletta, V., Blazquez, A., Bonin, J., Csatho, B., Cullather, R., Felikson, D., Fettweis, X., Forsberg, R., Gallee, H., Gardner, A., Gilbert, L., Groh, A., Gunter, B., Hanna, E., Harig, C., Helm, V., Horvath, A., Horwath, M., Khan, S., Kjeldsen, K. K., Konrad, H., Langen, P., Lecavalier, B., Loomis, B., Luthcke, S., McMillan, M., Melini, D., Mernild, S., Mohajerani, Y., Moore, P., Mouginot, J., Moyano, G., Muir, A., Nagler, T., Nield, G., Nilsson, J., Noel, B., Otosaka, I., Pattle, M. E., Peltier, W. R., Pie, N., Rietbroek, R., Rott, H., Sandberg-Sørensen, L., Sasgen, I., Save, H., Scheuchl, B., Schrama, E., Schröder, L., Seo, K.-W., Simonsen, S., Slater, T., Spada, G., Sutterley, T., Talpe, M., Tarasov, L., van de Berg, W. J., van der Wal, W., van Wessem, M., Vishwakarma, B. D., Wiese, D., Wouters, B., and The, I. T.: Mass balance of the Antarctic Ice Sheet from 1992 to 2017, Nature, 558, 219-222, https://doi.org/10.1038/s41586-018-0179-y, 2018.

Siegert, M., Ross, N., Corr, H., Kingslake, J., and Hindmarsh, R.: Late Holocene ice-flow reconfiguration in the Weddell Sea sector of West Antarctica, Quaternary Sci. Rev., 78, 98-107, https://doi.org/10.1016/j.quascirev.2013.08.003, 2013.
Siegert, M. J., Kingslake, J., Ross, N., Whitehouse, P. L., Woodward, J., Jamieson, S. S. R., Bentley, M. J., Winter, K., Wearing, M., Hein, A. S., Jeofry, H., and Sugden, D. E.: Major Ice Sheet Change in the Weddell Sea Sector of West Antarctica Over the Last 5,000 Years, Rev. Geophys., 57, 1197-1223, https://doi.org/10.1029/2019rg000651, 2019.

Smith, E. C., Baird, A. F., Kendall, J. M., Martín, C., White, R. S., Brisbourne, A. M., and Smith, A. M.: Ice fabric in an Antarctic ice stream interpreted from seismic anisotropy, Geophys. Res. Lett., 44, 3710-3718, https://doi.org/10.1002/2016g1072093, 2017.

Thorsteinsson, T., Kipfstuhl, J., and Miller, H.: Textures and fabrics in the GRIP ice core, J. Geophys. Res.-Oceans, 102, 26583 26599, https://doi.org/10.1029/97jc00161, 1997.

Tromp, J., Komattisch, D., and Liu, Q.: Spectral-Element and Adjoint Methods in Seismology, Commun. Comput. Phys., 3, 1-32, 2008.

Ukil, A., Braendle, H., and Krippner, P.: Distributed Temperature Sensing: Review of Technology and Applications, IEEE Sens. J., 12, 885-892, https://doi.org/10.1109/JSEN.2011.2162060, 2012.

Walter, F., Gräff, D., Lindner, F., Paitz, P., Köpfli, M., Chmiel, M., and Fichtner, A.: Distributed acoustic sensing of microseismic sources and wave propagation in glaciated terrain, Nat. Commun., 11, 2436, https://doi.org/10.1038/s41467-020-158246, 2020.

Wang, Y., Kipfstuhl, S., Azuma, N., Thorsteinsson, T., and Miller, H.: Ice-fabrics study in the upper $1500 \mathrm{~m}$ of the Dome C (East Antarctica) deep ice core, Ann. Glaciol., 37, 97-104, 2003.

Wearing, M. G. and Kingslake, J.: Holocene Formation of Henry Ice Rise, West Antarctica, Inferred From IcePenetrating Radar, J. Geophys. Res.-Earth, 124, 2224-2240, https://doi.org/10.1029/2018jf004988, 2019.

Weikusat, I., Jansen, D., Binder, T., Eichler, J., Faria, S. H., Wilhelms, F., Kipfstuhl, S., Sheldon, S., Miller, H., DahlJensen, D., and Kleiner, T.: Physical analysis of an Antarctic ice core-towards an integration of micro- and macrodynamics of polar ice, Philos. T. R. Soc. A, 375, 20150347, https://doi.org/10.1098/rsta.2015.0347, 2017. 